\title{
Activity level changes preceding runway trials: An index of conditioned fear
}

\author{
WARREN F. KLARE \\ Syracuse University, Syracuse, New York 13210
}

\begin{abstract}
Two experiments with hooded rats, in which activity level changes before runway trials are explored as an index of conditioned fear, are reported. Animals were dropped into a shock runway from an enclosed chamber where activity was monitored. Those that received shock in the runway showed a reliable decline in activity, significantly correlated with a reliable rise in running speed. When extinction trials were widely spaced (Exp. II), the activity-level measure accurately monitored both extinction and spontaneous recovery of fear. These results suggest the activity measure as a useful tool for investigation of fear in complex behavior.
\end{abstract}

Brown (1961) has suggested that a reliable index of conditioned fear must be developed before adequate direct tests of hypotheses about the role of fear in complex behavior in aversive stimulus situations can be undertaken. An analysis of behavior in fear situations by Miller (1951) indirectly suggests such an index. Addressing the observation made in his laboratory (Miller, 1948) and by Brown and Jacobs (1949), that the incompatible responses of both freezing and active flight appear to be strongly elicited by fear, Miller suggested that the actual behavior seen "... will depend on the external situation, as well as the fear [1951, pp. 442]." Bolles (1970) repeated the same basic idea when he suggested that the balance between freezing and fleeing (as SSDRs) can be altered "by varying the situation $[1970$, pp. 35]." Based on these analyses, an abrupt shift in cues around a fearful animal, from a set eliciting freezing to a set eliciting fleeing, should result in a corresponding shift in the animal's behavior from inactive to active. To test this possibility, an apparatus was developed that allowed the measurement of activity in an enclosed, inescapable (i.e., immobility-eliciting) chamber of a runway immediately before the $S$ was dropped into an open shock-grid runway leading to a safe goalbox.

As the same fear response to the runway cues should mediate and motivate both the activity decrease (freezing) in the enclosed chamber and the escape running on the grid, the measures of these behaviors should show a strong negative correlation. If so, the activity measure could be used as an index of the level of conditioned fear motivating the runway behavior.

\section{EXPERIMENT I}

\section{Method}

Subjects. Twenty-four male hooded rats of the Long-Evans strain, from the colony maintained by the Psychology Department at Syracuse University, served as Ss. They were 85-95 days of age at the beginning of the experiment and were maintained in individual cages on ad lib food and water throughout the experiment.

Apparatus. The apparatus was a modified version of the straight shock runway first described by Brown, Martin, and Morrow (1964). The startbox was divided into upper and lower chambers which were separated by a solenoid-activated trapdoor floor for the upper compartment. The Ss were placed into the dark gray upper chamber $(30 \mathrm{~cm}$ long $\times 11.5 \mathrm{~cm}$ wide $x 17 \mathrm{~cm}$ deep) through a hinged, clear Plexiglas lid. The lower chamber was the $46-\mathrm{cm}$ start end of a shock-grid runway $(11.5 \mathrm{~cm}$ wide $\mathrm{x}$ $20 \mathrm{~cm}$ high $\times 60 \mathrm{~cm}$ long), also painted dark gray. The shock grid consisted of $.30-\mathrm{cm}$ stainless steel grid bars, $1.25 \mathrm{~cm}$ apart, and mounted in Plexiglas side rails. At the end of the runway was a black, smooth-floored goalbox $(20 \mathrm{~cm}$ wide $\times 46 \mathrm{~cm}$ long $\mathrm{x}$ $20 \mathrm{~cm}$ deep) which was separated from the runway by a guillotine door. The runway and goalbox also had clear Plexiglas lids.

Shock was provided by an autotransformer set to $50 \mathrm{~V}$ $(60 \mathrm{~Hz})$ and was presented to the grid through a $10,000-\mathrm{ohm}$ series resistor. Activity levels in the upper chamber of the startbox were monitored, using an Alton Electronics ultrasonic motion detector, with output going to a Hunter Model $120 \mathrm{~A}$ Klockounter. A Hunter Model 11B timer was used to control the pretrial activity measurement period. Starting and running times were recorded to $1 / 100 \mathrm{sec}$ on Standard Electric timers which were triggered by the trapdoor drop, a photocell between the start and runway areas $(60 \mathrm{~cm}$ from goalbox) and a photocell at the entrance to the goalbox.

Procedure. At the beginning of the experiment, Ss were divided randomly into "shock" and "no-shock" groups of 12 each. All Ss were then handled for 7 days, the last 2 of which included exposure to the experimental room (while being heid by E). Two days of adaptation to the runway followed, consisting of $10 \mathrm{~min}$ exploration of the apparatus per day after placement in the goalbox with all doors open. On the next day, all of the 5 habituation, 6 acquisition, and 13 extinction trials were run. That sequence was chosen to allow 6 activity measurements after no-shock trials, 6 after acquisition trials, and 12 after extinction trials. A trial began when $S$ was placed in the upper chamber and E opened the goalbox door, starting a 10-sec period of activity monitoring in the chamber. The activity count was then terminated and the trapdoor solenoid was activated, dropping $\mathrm{S}$ to the grid floor below. During habituation trials, $\mathrm{S}$ was allowed $20 \mathrm{sec}$, after which it was guided to the goalbox. After $20 \mathrm{sec}$ in the goalbox, $S$ was removed and carried back for placement in the startbox to begin the next trial. On acquisition trials, the procedures were identical except that the shock grids were energized for Ss in the shock group. For the 13 extinction trials, the shock grid was de-energized for all Ss. 


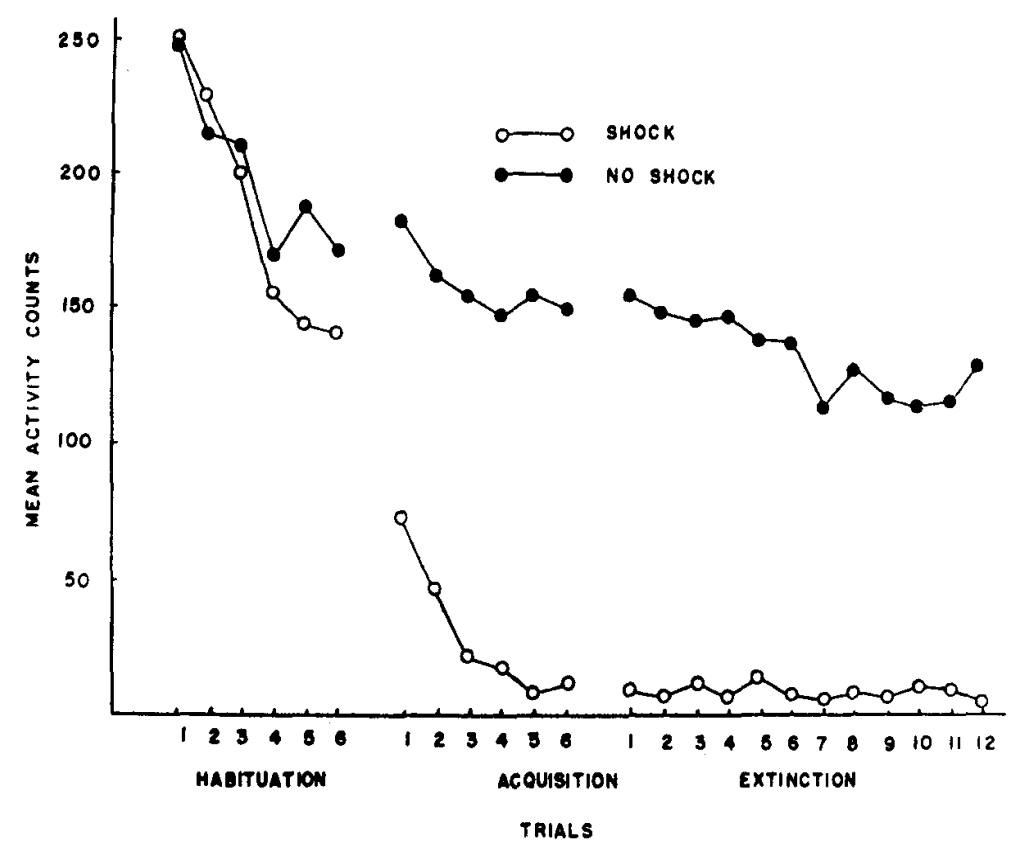

Fig. 1. Mean activity levels on single trials for shocked and nonshocked Ss, as recorded by an ultrasonic motion detector in the startbox of a runway immediately before a trial (massed trials).

\section{Results}

A plot of the mean activity scores for shock and no-shock Ss across trials is presented in Fig. 1. A two-factor mixed analysis of variance was performed separately for habituation, acquisition, and extinction phases, with group (shock or no-shock) as the between factor and trials as the within factor. During habituation, the only significant effect was the main effect of trials $(\mathrm{F}=24.43, \mathrm{df}=5 / 110, \mathrm{p}<.001)$.

During acquisition, the striking decline in activity of the shocked Ss yielded a highly significant groups difference $(F=32.17, \mathrm{df}=1 / 22, \mathrm{p}<.001)$. The change across trials was again significant $(\mathrm{F}=7.96, \mathrm{df}=5 / 110$, $\mathrm{p}<.001$ ). Running speeds in the shock group showed a typical acquisition function, with the mean asymptote running speed approximately $70 \mathrm{~cm} / \mathrm{sec}$.

In the extinction phase, the groups difference was again highly significant $(\mathrm{F}=40.133, \mathrm{df}=1 / 22$, $\mathrm{p}<.001)$. Here also, both the change across trials and the Groups by Trials interaction were significant $(\mathrm{F}=2.66, \mathrm{df}=11 / 242, \quad \mathrm{p}<.01, \quad$ and $\mathrm{F}=2.037$, $\mathrm{df}=11 / 242, \mathrm{p}<.05$, respectively).

On the first extinction trial, the correlation between activity in the upper startbox and running speed in the runway was highly significant $(\mathrm{r}=-.712, \mathrm{t}=4.76$, $\mathrm{df}=22, \mathrm{p}<.001)$.

One perplexing observation was that, although the running speeds of shocked animals were decreasing across the 12 extinction trials (first trial mean run speed $=66.5 \mathrm{~cm} / \mathrm{sec}$, last trial mean run speed $=46.5 \mathrm{~cm} / \mathrm{sec}$, $\mathrm{t}=2.63, \mathrm{df}=11, \mathrm{p}<.05$ ), there was no corresponding rise in the pretrial activity scores. Such a rise was of course anticipated, as the fear response was presumably extinguishing. Because of the possible confounding effects of fatigue and postshock emotionality on the activity scores of animals given such massed trials, a second experiment was conducted in which extinction trials were spaced to allow the dissipation of these effects.

\section{EXPERIMENT II}

\section{Method}

Subjects. Female hooded rats $(\mathrm{N}=16), 90-100$ days of age at the beginning of the experiment, obtained from the colony maintained by the Psychology Department at Syracuse University, were used. Housing and the feeding and watering schedules were the same as in Experiment I.

Apparatus and Procedure. Apparatus and procedure were the same as in Experiment I, except for the number and spacing of trials. All Ss were run in squads of four, with trials given at the rate of 5/day. The intertrial interval for each $S$ was approximately $3 \mathrm{~min}$. Following 1 day for habituation and 2 days of shock (or no-shock) trials, extinction trials were continued for 8 days, yielding a total of 40 extinction trials.

\section{Results}

A plot of the activity levels of the shock and no-shock groups at the last acquisition and all extinction days is presented in Fig. 2. In contrast with the previous experiment, a systematic rise in activity scores across extinction trials does appear in these data. A two-factor mixed analysis of variance was performed on the median activity scores within a five-trial session for all Ss, with groups as the between-S factor and extinction session the within-S factor. The groups difference was significant $(F=20.99, \mathrm{df}=1 / 14, \mathrm{p}<.001)$, as was the main effect of trials and the Groups by Trials interaction $(\mathrm{F}=6.33, \mathrm{df}=7 / 98, \mathrm{p}<.001$, and $\mathrm{F}=2.75, \mathrm{df}=7 / 98$, $\mathrm{p}<.025$, respectively). The mean trial on which 
Fig. 2. Mean activity levels in the startbox for shocked and nonshocked Ss, as recorded by an ultrasonic motion detector, for last day of shock trials and 8 days of extinction trials (5 trials/day on all days).

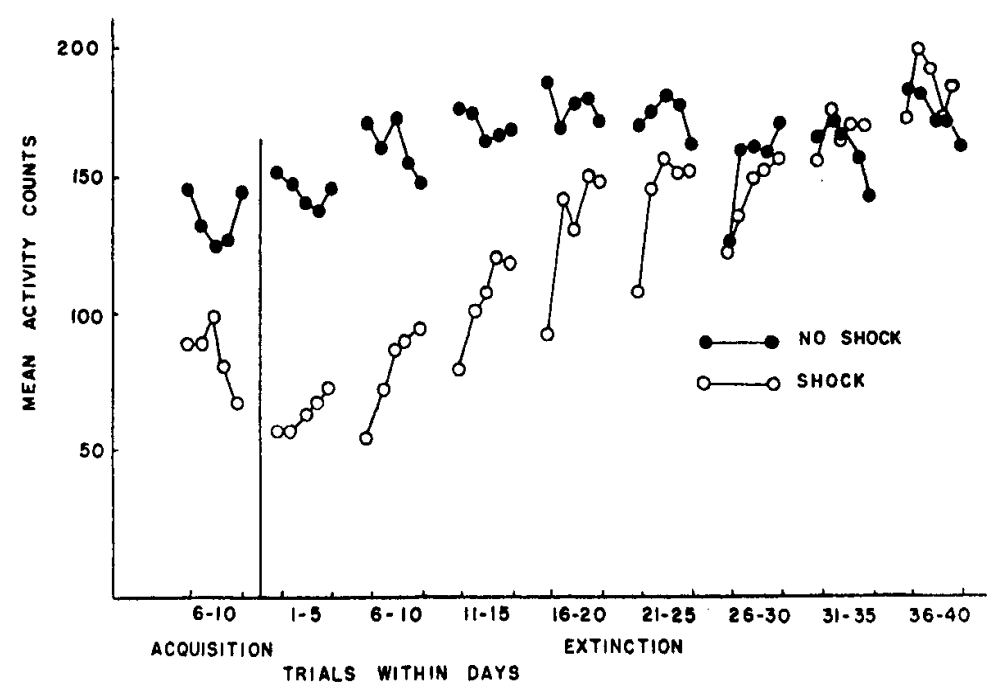

shocked Ss reached the extinction criterion $(20 \mathrm{sec}$ in runway) was 14.8 .

A striking feature of these data is a strong "spontaneous recovery" of freezing between sessions. Such a phenomenon in fear situations is rarely observed, according to McAllister and McAllister (1971). There was no corresponding effect in the running speed data, though such an effect, if present, could be obscured by a warm-up effect, undoubtedly important in active running, while presumably an inconsequential variable in crouching behavior.

\section{DISCUSSION}

Taken together, these experiments support the Miller hypothesis that fear modifies an organism's response hierarchy toward both fleeing and freezing, and that the cues of the immediate situation will determine which of the two incompatible response tendencies will occur. They are also consistent with the numerous other observations of decreases in activity in some fear situations and activity increases in others (e.g., Brown, 1961; Blanchard \& Blanchard, 1969a, b).

The very clear-cut and powerful differences that occur in the freezing measure during acquisition, and the systematic changes seen during extinction (given appropriate distribution of trials), clearly support the use of such a measure as an index of the level of conditioned fear of animals in runway or one-way avoidance situations. As a response of the organism when fear is elicited, this activity-reduction appears to be relatively simple and stable over an extended time, thus avoiding some of the difficulties of interpretation seen with other indices (Rescorla \& Solomon, 1967). Its immediacy of occurrence renders it superior to those indices which necessitate one's concern with the development and time course of the index response, as well as the development of fear (e.g., McAllister \& McAllister, 1971). The obvious multiple determination of activity decreases (e.g., fatigue, "boredom," shock aftereffects, etc.) remains a problem, however, demanding the use of appropriate procedures and control groups.

A major contribution of such a measure is that it can be used concurrently with, but relatively independently of, a variety of more complex fear-motivated behaviors. It may thus be used to shed light on some of the paradoxical, or otherwise unusual, effects in aversive-stimulus situations (e.g., vicious-circle behavior, the Kamin effect, various unusual avoidance effects, etc.). One such application has already been successful (Klare,
1974). This ability becomes especially significant in the light of recent pessimistic evaluations of the state of understanding of fear and its related behaviors (e.g., Bolles, 1967, p. 313).

This measurement procedure can be added in any run'say or one-way avoidance situation where a trapdoor drop is an acceptable means of trial initiation. The method produces relatively little intrusion on the animal and its environmental situation, apart from the probably detectable $40,000-\mathrm{Hz}$ signal. However, the continued high level of activity in the no-shock group Ss indicates that neither the dropping procedure nor the ultrasonic frequencies are significantly aversive, in themselves.

\section{REFERENCES}

Blanchard, R. J., \& Blanchard, D. C. Crouching as an index of fear. Journal of Comparative \& Physiological Psychology, $1969 \mathrm{a}, 67,370-375$.

Blanchard, R. J., \& Blanchard, D. C. Passive and active reactions to fear-eliciting stimuli. Journal of Comparative \& Physiological Psychology, 1969b, 68, 129-135.

Bolles, R. C. Theory of motivat ion. New York: Harper, 1967.

Bolles, R. C. Species-specific defense reactions and avoidance learning. Psychological Review, 1970, 77, 32-48.

Bolles, R. C. Species-specific defense reactions. In F. R. Brush (Ed.), Aversive conditioning and learning. New York: A cademic Press, 1971. Pp.183-233.

Brown, J. S. The motivation of behavior. New York: McGraw-Hill, 1961.

Brown, J. S., \& Jacobs, A. The role of fear in the motivation and acquisition of responses. Journal of Experimental Psychology, $1949,39,747-759$.

Brown, J. S., Martin, R. C., \& Morrow, M. W. Self-punitive behavior in the rat: Facilitative effects of punishment on resistance to extinction. Journal of Comparative \& Physiological Psychology, 1964, 57, 127-133.

Klare, W. F. Conditioned fear and post-shock emotionality in vicious-circle behavior. Journal of Comparative \& Physiological Psychology, 1974, 87, 364-372.

McAllister, W. R., \& McAllister, D. E. Behavioral measurement of conditioned fear. In F. R. Brush (Ed.), Aversive conditioning and learning. New York: Academic Press, 1971. Pp. 105-179.

Miller, N. E. Studies of fear as an acquirable drive: Fear as motivation and fear-reduction as reinforcement in the learning of new responses. Journal of Experimental Psychology, 1948, 38, 89-101.

Miller, N. E. Learnable drives and rewards. In S. S. Stevens (Ed.), Handbook of experimental psychology. New York: Wiley, 1951. Pp. 435-472.

Rescorla, R. A., \& Solomon, R. L. Two-process learning theory: Relationships between Pavlovian conditioning and instrumental learning. Psychological Review, 1967, 74, 151-182. 